\title{
Correlation between circulating tumor cells and D-D and platelet in patients with pulmonary malignancies
}

\author{
LIJUN YANG ${ }^{*}$, HAI DONG ${ }^{*}$, ZIXUAN LI, YONGYUE PAN, LA QU and ZHIWEN TAN \\ School of Medicine, Tibet University, Lhasa, Tibet 850000, P.R. China
}

Received July 25, 2017; Accepted November 20, 2017

DOI: $10.3892 / \mathrm{ol} .2017 .7595$

\begin{abstract}
The aim of the present study was to investigate the correlation between circulating tumor cells (CTC) and D-dimer (D-D) and platelet (PLT) in patients with pulmonary malignancies. A total of 98 patients with lung cancer admitted to West China Hospital, Sichuan University, from June 2016 to February 2017 were enrolled in the present study. D-D and PLT levels were measured in the fasting elbow vein of the patients. The expression of CTC in peripheral blood was detected by negative separation using immunomagnetic beads and immunocytochemical staining. The correlation between CTC and D-D and PLT in patients with lung cancer was analyzed. The mean level of D-D in the peripheral blood of 98 patients was $1.80 \pm 1.63 \mu \mathrm{g} / \mathrm{l}$, and the level of D-D was correlated with distant metastasis $(\mathrm{P}<0.05)$. The mean level of PLT in peripheral blood was $305.53 \pm 141.22 \times 10^{9} / 1$ in 98 patients, and the level of PLT was correlated with patient age, clinical stage and distant metastasis $(\mathrm{P}<0.05)$. The levels of D-D, PLT and distant metastasis were significantly higher in CTC-positive than in CTC-negative patients $(\mathrm{P}<0.05)$. Therefore, $\mathrm{CTC}$ can predict the distant metastasis of lung cancer, and the incidence of distant metastasis is high in patients with hypercoagulable state.
\end{abstract}

\section{Introduction}

The mortality rate of lung cancer ranks first among all malignancies and poses a serious threat to human health. The 5-year survival rate is less than $15 \%$, and the incidence is on the increase annually. Most patients develop distant organ metastasis, such as bone, brain, liver, and adrenal gland with progression of the disease, which has a serious impact on the prognosis $(1,2)$.

As one of the necessary pathways for distant metastasis of the tumor is the blood circulation system, tumor cells in the blood circulation system have the same genetic and cytological characteristics as tumor cells in the primary tumor. Therefore,

Correspondence to: Dr Lijun Yang, School of Medicine, Tibet University, Jiri Street, Lhasa, Tibet 850000, P.R. China

E-mail: 519420803@qq.com

*Contributed equally

Key words: lung cancer, circulating cells, D-dimer, platelet circulating tumor cells (CTC) of lung cancer patients is a major indicator of assessing the patient's condition (3). Platelet (PLT) is an indispensable part of the blood circulation, playing an irreplaceable role in the metastasis of CTC (4). Plasma D-dimer (D-D) is a specific degradation product of cross-linked fibrin, which is a specific marker of secondary fibrinolysis and hypercoagulability in vivo (5).

Therefore, in the present study, the correlation between CTC and D-D, and PLT was examined in lung cancer patients, in order to provide a reference for late clinical treatment. The results showed that, CTC is able to predict the distant metastasis of lung cancer, and the incidence of distant metastasis is high in patients with the hypercoagulable state.

\section{Materials and methods}

General information. A total of 98 patients with malignant lung cancer admitted to West China Hospital, Sichuan University (Sichuan Sheng, China) from June, 2016 to February, 2017 were selected as subjects of the study, including 51 males and 47 females, aged 48-79 years; mean, $60.63 \pm 7.93$ years. The present study was approved by the Ethics Committee of Tibet Traditional Medical College (Tibet, China). Signed written informed consent was obtained from the patients and/or guardians.

Inclusion criteria. Inclusion criteria for the study were: i) Patients diagnosed as lung cancer clinically; ii) successful removal of tumor via surgery; iii) without anticoagulant therapy or antitumor treatment; and iv) informed consent was voluntarily signed.

Exclusion criteria. Exclusion criteria for the study were: i) Patients with other malignant tumors; ii) patients with severe heart, liver and kidney dysfunction; iii) patients with infectious diseases or thrombotic disease; and iv) taking hormones or surgical history within 6 months.

CTC-positive diagnostic criteria. CTC-positive diagnostic criteria (6) were determined under a light microscope (Olympus, Tokyo, Japan), and were as follows: i) Integrate cell membrane, Pan-CK staining positive, cytoplasm was brown or dark blue; ii) nuclear cytoplasmic ratio abnormalities; iii) cell diameter greater than $10 \mu \mathrm{m}$. Regarding morphology: i) Complete nucleus and cell morphology were observed under 
Table I. D-D level and the correlation with clinicopathological characteristics of patients with lung cancer.

\begin{tabular}{|c|c|c|c|c|}
\hline Item & No. of cases (n) & D-D level $(\mu \mathrm{g} / \mathrm{l})$ & t-test & P-value \\
\hline Age (years) & & & 1.767 & 0.080 \\
\hline$\geq 60$ & 52 & $1.76 \pm 1.03$ & & \\
\hline$<60$ & 46 & $1.68 \pm 1.06$ & & \\
\hline Sex & & & 1.617 & 0.180 \\
\hline Male & 51 & $1.79 \pm 1.58$ & & \\
\hline Female & 47 & $1.81 \pm 1.23$ & & \\
\hline Clinical stage & & & 1.956 & 0.052 \\
\hline $\mathrm{I}$ & 12 & $1.55 \pm 0.91$ & & \\
\hline II & 21 & $1.68 \pm 1.16$ & & \\
\hline III & 28 & $1.39 \pm 0.89$ & & \\
\hline IV & 37 & $1.74 \pm 1.32$ & & \\
\hline Pathologic type & & & 1.926 & 0.063 \\
\hline Squamous cell carcinoma & 44 & $1.89 \pm 0.95$ & & \\
\hline Adenocarcinoma & 33 & $1.79 \pm 1.05$ & & \\
\hline Small cell carcinoma & 21 & $1.37 \pm 0.99$ & & \\
\hline Distant metastasis & & & 2.253 & 0.038 \\
\hline No & 62 & $1.35 \pm 0.78$ & & \\
\hline Yes & 36 & $2.45 \pm 1.13$ & & \\
\hline
\end{tabular}

D-D, D-dimer.

light microscope; and ii) the cells were oval, round or long, or long and the diameter was more than $10 \mu \mathrm{m}$.

\section{Materials and methods}

Instruments and reagents. For D-D detection, an automatic hemagglutination instrument and its supporting reagents (Diagnostica Stago, Gennevilliers, France) were used. For PLT detection, automatic blood cell analyzer and its supporting reagents (Mindray BC6088; Mindray, Shenzhen, China) were employed. Morning fasting elbow vein blood D-D and PLT levels were also measured. The expression of CTC in peripheral blood was detected by negative separation with immunomagnetic beads and immunocytochemical staining.

Methods. The blood and lymphocyte separation medium was placed at room temperature from 18 to $25^{\circ} \mathrm{C}$ for $30 \mathrm{~min}$, and $7.5 \mathrm{ml}$ of phosphate buffer and $7.5 \mathrm{ml}$ of anticoagulation was mixed in a $50 \mathrm{ml}$ centrifuge tube, added into a centrifuge tube with $15 \mathrm{ml}$ of lymphocyte separation medium, and centrifuged for $30 \mathrm{~min}$ at 3,649 $\mathrm{x} \mathrm{g}$ at room temperature. The banded plasma mononuclear cells were aspirated and added with 5-fold phosphate buffer, mixed completely, and centrifuged at $2,053 \mathrm{x}$ g for $15 \mathrm{~min}$ at room temperature. The supernatant was separated and the lower layer was centrifuged twice.

After the cells were precipitated, they were resuspended in $80 \mu \mathrm{l}$ of magnetic bead buffer and $20 \mu \mathrm{l}$ of mouse anti-human CD45 monoclonal antibody (dilution, 1:200; no. 130-098-043; Miltenyi Biotec $\mathrm{GmbH}$, Bergisch Gladbach, Germany) was added. The antibody was bound to magnetic beads and incubated into $4^{\circ} \mathrm{C}$ refrigerator for $5 \mathrm{~min}$. Subsequently, the volume of bead buffer was added 20 times and centrifuged for $10 \mathrm{~min}$ at 2,053 x g at room temperature. The supernatant was separated and $500 \mu 1$ of buffer was added to resuspend the cells. The resuspended cells passed through the MS column and were rinsed twice with $500 \mu \mathrm{l}$ of the bead buffer to collect the effluent from the column. The cells were again centrifuged at room temperature for $10 \mathrm{~min}$ at $2,053 \mathrm{x} \mathrm{g}$, the supernatant was separated, the precipitation was evenly applied to the anti-off slides, air dried at room temperature, and fixed using $4 \%$ paraformaldehyde for $10 \mathrm{~min}$. The cells were then washed with $7.5 \mathrm{ml}$ phosphate buffer for $5 \mathrm{~min}$, three times, followed by the addition of anti-spectral cytokeratin (Pan-CK; Cell Signaling Technology, Inc., Danvers, MA, USA), and incubation in a $4^{\circ} \mathrm{C}$ refrigerator for $12 \mathrm{~h}$. The cells were then rinsed with $7.5 \mathrm{ml}$ phosphate buffer, and EnVision working solution was added to the rat anti-mouse secondary polyclonal antibody (diilution, 1:800; no. 130-098-105), prior to incubation in a thermostat at $37^{\circ} \mathrm{C}$ for $20 \mathrm{~min}$. The cells were washed again with $7.5 \mathrm{ml}$ of phosphate buffer, developed with diaminobenzidine, and then counterstained with hematoxylin for $5 \mathrm{~min}$. Finally, the cells were observed under a light microscope (Mantis Elite, Vision Engineering Ltd.) following steps including differentiation, dehydration, transparent, and neutral gum seal-light.

Observation indicators. The D-D normal range was $0-0.55 \mu \mathrm{g} / 1$, and the PLT normal range was (125-350) $\times 10^{9} / 1$.

Statistical analysis. SPSS 19.0 software (SPSS, Inc., Beijing Xinmeijiahong Technology Co., Ltd.) was used for statistical analysis. Measurement data were determined using the t-test, and countable data were determined using the $\chi^{2}$ test. $\mathrm{P}<0.05$ was considered to indicate a statistically significant difference. 
Table II. Relationship between PLT levels and clinicopathological characteristics of lung cancer.

\begin{tabular}{|c|c|c|c|c|}
\hline Item & No. of cases $(n)$ & PLT level (x109/1) & t-test & P-value \\
\hline Age (years) & & & 3.376 & 0.001 \\
\hline$\geq 60$ & 52 & $367.66 \pm 112.46$ & & \\
\hline$<60$ & 46 & $198.74 \pm 108.53$ & & \\
\hline Sex & & & 1.637 & 0.110 \\
\hline Male & 51 & $290.55 \pm 149.38$ & & \\
\hline Female & 47 & $293.76 \pm 138.71$ & & \\
\hline Clinical stage & & & 2.580 & 0.010 \\
\hline $\mathrm{I}$ & 12 & $120.46 \pm 16.46$ & & \\
\hline II & 21 & $143.75 \pm 18.37$ & & \\
\hline III & 28 & $261.74 \pm 35.89$ & & \\
\hline IV & 37 & $413.92 \pm 61.34$ & & \\
\hline Pathologic type & & & 1.432 & 0.303 \\
\hline Squamous cell carcinoma & 44 & $321.47 \pm 139.73$ & & \\
\hline Adenocarcinoma & 33 & $286.83 \pm 127.37$ & & \\
\hline Small cell carcinoma & 21 & $279.64 \pm 141.46$ & & \\
\hline Distant metastasis & & & 2.504 & 0.022 \\
\hline No & 62 & $215.78 \pm 89.43$ & & \\
\hline Yes & 36 & $446.66 \pm 91.57$ & & \\
\hline
\end{tabular}

PLT, platelet.

Table III. Correlation between lung cancer and CTC and D-D, PLT levels, and distant metastasis.

\begin{tabular}{lcccc}
\hline Groups & No. of cases $(\mathrm{n})$ & D-D level $(\mu \mathrm{g} / \mathrm{l})$ & PLT level $\left(\mathrm{x} 10^{9} / \mathrm{l}\right)$ & Distant metastasis $(\mathrm{n}, \%)$ \\
\hline CTC-positive & 56 & $2.39 \pm 2.01$ & $342.55 \pm 129.47$ & $29(51.79)$ \\
CTC-negative & 42 & $1.04 \pm 1.06$ & $236.49 \pm 118.95$ & $6(14.29)$ \\
$\chi^{2} / \mathrm{t}$-test & & 2.801 & 2.678 & 8.676 \\
P-value & & 0.006 & 0.009 & 0.004 \\
\hline
\end{tabular}

CTC, circulating tumor cells; D-D, D-dimer; PLT, platelet.

\section{Results}

Association between D-D level and clinicopathological characteristics of lung cancer. The average D-D level in the peripheral blood of 98 patients was $1.80 \pm 1.63 \mu \mathrm{g} / 1$, and the level of D-D was correlated with distant metastasis $(\mathrm{P}<0.05)$ (Table I).

Association between PLT level and clinicopathological characteristics of lung cancer. The average level of PLT in the peripheral blood of 98 patients was $305.53 \pm 141.22 \times 10^{9} / 1$. The PLT level was correlated with patient age, clinical stage and distant metastasis $(\mathrm{P}<0.05)$ (Table II).

Correlation between CTC and D-D, PLT level and distant metastasis in patients with lung cancer. The incidence of D-D, PLT and distant metastasis in the CTC-positive group was significantly higher than that in the CTC-negative group, and the difference was statistically significant $(\mathrm{P}<0.05)$ (Table III).

\section{Discussion}

Pulmonary malignant tumor has a high rate of recurrence and distant metastasis, thus the 5-year survival rate is low (7). The hyperplastic and hypercoagulable states of the patients are closely related to the local infiltration and distant metastasis of tumor cells. The tumor cells can affect the coagulation system by secreting inflammatory cytokines, expressing the coagulation protein and the adhesion of normal cells. Additionally, blood vessel endothelial cell injury, blood hypercoagulable state and other factors of malignant tumor patients may lead to distant metastasis (8).

CTC, as a kind of cell in the circulatory system with a high degree of metastasis and high activity, is important in tumor cell metastasis. On the one hand, CTC is a subtype of tumor stem cells. On the other hand, the tumor microenvironment of CTC provides the appropriate conditions for maintaining the survival of tumor cells, and can also provide a metastatic path for tumor cells through complex and extensive intercellular interactions (9). Previous studies have suggested that, in many tumors, D-D and 
PLT levels are negatively correlated with the survival of patients and inhibition of PLT activity (10). The reduction of D-D levels is effective for reducing the distant metastasis of malignant tumors, which indicates that PLT and D-D may be involved in maintaining CTC survival and metastatic infiltration.

Therefore, the present study explored the correlation between lung cancer and CTC and D-D and PLT, in order to provide a reference for late clinical treatment.

Tumor cells can secrete cancer coagulation, tissue and other coagulation-related factors, play a role in the coagulation process, activate prothrombin, turning the environment of tumor cells into a hypercoagulable state, thereby forming thrombosis (11). At the same time, the hypercoagulable state can improve the adhesion ability of tumor emboli on the target organ vascular wall, increasing the chance of metastases (12). D-D is a product of cross-linked fibrinolytic decomposition by fibrinolytic enzymes, and serves as an important molecular marker for the diagnosis of fibrinolytic system hyperthyroidism and hypercoagulable state. Moreover, enhanced D-D levels indicate that patients have secondary fibrinolytic system hyperactivity (13). Part of the PLT agglutination activity factor can be secreted by tumor cells, promoting PLT aggregation and adhesion on the surface of tumor cells, releasing PLT-derived growth factor, which can promote tumor cell growth. Thus, the number of PLT and the degree of activation are somewhat correlated with the distant metastasis of tumor cells (14). At the same time, PLT, as a cofactor of the activation of coagulation and tissue factor, can be overexpressed in tumor cells and thus promote PLT aggregation. Thus, activation of PLT can also be combined with fibrin to form tumor cell-fibrin-TCIPA (15). The tumor cells, not only promote PLT aggregation, but also activate PLT through the release of thromboxane A2, adenosine diphosphate and other tumor-associated proteins. Under the effect of activation and aggregation, PLT can form a 'physical barrier' around the CTC to prevent CTC from being damaged in the circulation system (16). The results of the present study have shown that the D-D level in the peripheral blood of 98 patients was $1.80 \pm 63 \mu \mathrm{g} / 1$ and D-D was correlated with distant metastasis $(\mathrm{P}<0.05)$. The level of PLT in the peripheral blood of 98 patients was $305.53 \pm 141.22 \times 10^{9} / 1$, and the PLT level was correlated with patient age, clinical stage and distant metastasis $(\mathrm{P}<0.05)$. The levels of D-D, PLT and distant metastasis in CTC-positive patients were significantly higher than those in CTC-negative patients $(\mathrm{P}<0.05)$. This result also suggests that high levels of D-D and PLT are closely related to postoperative distant metastases in patients with pulmonary malignancies.

In conclusion, CTC is able to predict the distant metastasis of lung cancer, and patients with hypercoagulable state have a higher incidence of distant metastasis. This suggests that in clinical treatment, for some lung cancer patients without contraindications, anticoagulant therapy can be provided, thereby reducing the recurrence and distant metastasis rates of tumor, improving survival and prognosis.

\section{Acknowledgements}

The present study was supported by the Natural Science Foundation of Tibet (no. 2015212-13-1) and the University of Tibet Mount Everest Scholar Talent Development Support Program-Outstanding Young Scholar.

\section{References}

1. Tjensvoll K, Nordgård $\mathrm{O}$ and Smaaland R: Circulating tumor cells in pancreatic cancer patients: Methods of detection and clinical implications. Int J Cancer 134: 1-8, 2014.

2. Kaifi JT, Kunkel M, Das A, Harouaka RA, Dicker DT, Li G, Zhu J, Clawson GA, Yang Z, Reed MF, et al: Circulating tumor cell isolation during resection of colorectal cancer lung and liver metastases: A prospective trial with different detection techniques. Cancer Biol Ther 16: 699-708, 2015.

3. Bidard FC, Madic J, Mariani P, Piperno-Neumann S, Rampanou A, Servois V, Cassoux N, Desjardins L, Milder M, Vaucher I, et al: Detection rate and prognostic value of circulating tumor cells and circulating tumor DNA in metastatic uveal melanoma. Int J Cancer 134: 1207-1213, 2014.

4. Shi W, Paproski RJ, Moore R and Zemp R: Detection of circulating tumor cells using targeted surface-enhanced Raman scattering nanoparticles and magnetic enrichment. J Biomed Opt 19: 056014, 2014.

5. Fu BH, Fu ZZ, Meng W, Gu T, Sun XD and Zhang Z: Platelet VEGF and serum TGF- $\beta 1$ levels predict chemotherapy response in non-small cell lung cancer patients. Tumour Biol 36: 6477-6483, 2015

6. Möckelmann N, Laban S, Pantel K and Knecht R: Circulating tumor cells in head and neck cancer: Clinical impact in diagnosis and follow-up. Eur Arch Otorhinolaryngol 271: 15-21, 2014.

7. Abid L, Bahloul A, Frikha Z, Mallek S, Abid D, Akrout M, Hentati $M$ and Kammoun S: Myocardial infarction and normal coronary arteries: The experience of the cardiology department of Sfax, Tunisia. Intern Med 51: 1959-1967, 2012.

8. Das A, Kunkel M, Joudeh J, Dicker DT, Scicchitano A, Allen JE, Sarwani N, Yang Z, Kaifi J, Zhu J, et al: Clinico-pathological correlation of serial measurement of circulating tumor cells in 24 metastatic colorectal cancer patients receiving chemotherapy reveals interpatient heterogeneity correlated with CEA levels but independent of KRAS and BRAF mutation. Cancer Biol Ther 16: 709-713, 2015.

9. Gharbaran R, Park J, Kim C, Goy A and Suh KS: Circulating tumor cells in Hodgkin's lymphoma - a review of the spread of HL tumor cells or their putative precursors by lymphatic and hematogenous means, and their prognostic significance. Crit Rev Oncol Hematol 89: 404-417, 2014.

10. Broersen LH, van Pelt GW, Tollenaar RA and Mesker WE: Clinical application of circulating tumor cells in breast cancer. Cell Oncol 37: 9-15, 2014

11. Rank A, Liebhardt S, Zwirner J, Burges A, Nieuwland R and Toth B: Circulating microparticles in patients with benign and malignant ovarian tumors. Anticancer Res 32: 2009-2014, 2012.

12. Groeneveld D, Porte RJ and Lisman T: Thrombomodulin-modified thrombin generation testing detects a hypercoagulable state in patients with cirrhosis regardless of the exact experimental conditions. Thromb Res 134: 753-756, 2014.

13. Lee JK, Hong YJ, Han CJ, Hwang DY and Hong SI: Clinical usefulness of serum and plasma vascular endothelial growth factor in cancer patients: Which is the optimal specimen? Int J Oncol 17: 149-152, 2000.

14. Vande Vusse LK, Madtes DK, Guthrie KA, Gernsheimer TB, Curtis JR and Watkins TR: The association between red blood cell and platelet transfusion and subsequently developing idiopathic pneumonia syndrome after hematopoietic stem cell transplantation. Transfusion 54: 1071-1080, 2014.

15. Zhu M, Xu W, Wang BL and Su H: Hemostatic function and transfusion efficacy of apheresis platelet concentrates treated with gamma irradiation in use for thrombocytopenic patients. Transfus Med Hemother 41: 189-196, 2014.

16. Pickens B, Mao Y, Li D, Siegel DL, Poncz M, Cines DB and Zheng XL: Platelet-delivered ADAMTS13 inhibits arterial thrombosis and prevents thrombotic thrombocytopenic purpura in murine models. Blood 125: 3326-3334, 2015.

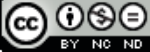

This work is licensed under a Creative Commons Attribution-NonCommercial-NoDerivatives 4.0 International (CC BY-NC-ND 4.0) License. 